Western Washington University

Western CEDAR

\title{
The impact of magnetic resonance imaging on juror perceptions of guilt
}

Christopher M. (Christopher Michael) Jackson

Western Washington University

Follow this and additional works at: https://cedar.wwu.edu/wwuet

Part of the Experimental Analysis of Behavior Commons

\section{Recommended Citation}

Jackson, Christopher M. (Christopher Michael), "The impact of magnetic resonance imaging on juror perceptions of guilt" (2012). WWU Graduate School Collection. 260.

https://cedar.wwu.edu/wwuet/260

This Masters Thesis is brought to you for free and open access by the WWU Graduate and Undergraduate Scholarship at Western CEDAR. It has been accepted for inclusion in WWU Graduate School Collection by an authorized administrator of Western CEDAR. For more information, please contact westerncedar@wwu.edu. 
The Impact of Magnetic Resonance Imaging on

Juror Perceptions of Guilt

\author{
By \\ Christopher M. Jackson \\ Accepted in Partial Completion \\ Of the Requirements for the Degree \\ Master of Science \\ Kathleen L. Kitto, Dean of the Graduate School
}

ADVISORY COMMITTEE

Chair, Dr. Jennifer Devenport

Dr. McNeel Jantzen

Dr. Joseph Trimble 


\section{MASTER'S THESIS}

In presenting this thesis in partial fulfillment of the requirements for a master's degree at Western Washington University, I grant to Western Washington University the nonexclusive royalty-free right to archive, reproduce, distribute, and display the thesis in any and all forms, including electronic format, via any digital library mechanisms maintained by WWU.

I represent and warrant this is my original work, and does not infringe or violate any rights of others. I warrant that I have obtained written permissions from the owner of any third party copyrighted material included in these files.

I acknowledge that I retain ownership rights to the copyright of this work, including but not limited to the right to use all or part of this work in future works, such as articles or books. Library users are granted permission for individual, research and non-commercial reproduction of this work for educational purposes only. Any further digital posting of this document requires specific permission from the author.

Any copying or publication of this thesis for commercial purposes, or for financial gain, is not allowed without my written permission.

Christopher M. Jackson

February 1, 2013 
The Impact of Magnetic Resonance Imaging on

Juror Perceptions of Guilt

\author{
A Thesis \\ Presented to \\ The Faculty of \\ Western Washington University \\ In Partial Fulfillment \\ Of the Requirements for the Degree \\ Master of Science
}

By

Christopher M. Jackson

December 2012 


\begin{abstract}
This study examined the impact of MRI-based evidence on juror perceptions of guilt in a criminal case. Jury eligible undergraduates read one of three mock trial summaries of a murder case wherein MRI evidence was manipulated: (1) MRI evidence with accompanying neuroimages, (2) MRI evidence without accompanying brain images, or (3) no MRI evidence. The proportion of guilty verdicts rendered was statistically similar across all conditions. In addition, participants did not list MRI evidence as the most influential piece of evidence for their verdict. Based on the results of this study it appears that MRI-based evidence and neuroimages do not significantly influence the juror decision making processes. Implications and future directions are discussed.
\end{abstract}

Keywords: MRI, murder, forensic evidence, juror decision making 


\section{Table of Contents}

Abstract _ iv

Introduction

Method __ 11

Results _ 15

Discussion

References _ـ 29

List of Tables _ 35

Appendices _ـ 39 
The Impact of Forensic Evidence on Juror Perceptions of Guilt

Forensic evidence includes polygraph evidence, fingerprint matching, deoxyribonucleic acid (DNA) analysis, and a variety of neuroimaging techniques [e.g., magnetic resonance imaging (MRI)]. In its courtroom application, forensic evidence is circumstantial—it requires a juror to make a decision regarding the connection between the evidence and the facts. Forensic evidence forms the basis for two types of arguments: character- and location-based arguments. Attorneys may use the evidence to suggest the defendant is lying (character-based; e.g., polygraph evidence) or use it to suggest the defendant was present at the scene of the crime (location-based; e.g., fingerprint matching, DNA analysis).

Empirical research examining the effect of forensic evidence on juror perceptions of guilt often involve presenting mock jurors with a trial summary that differs in the types of evidence presented (McAllister \& Bregman, 1986; McCabe, Castel, \& Rhodes, 2011; Myers \& Arbuthnot, 1997; Myers, Rosol, \& Boelter, 2003). Participants are asked to render a verdict as if they were present at the trial. If the proportion of guilty verdicts in all conditions is similar, then it is assumed that the forensic evidence does not influence juror verdicts. Using this aforementioned methodology, this study assesses the impact of MRI on juror perceptions of guilt.

Independent of empirical research, courtroom judges maintain the belief that forensic evidence may improperly [emphasis added] influence the jury. Court decisions reflect the concerns that forensic evidence may usurp the role of jurors as triers of facts (U.S. v. Scheffer, 1998), may cause juror confusion and prejudice, and may not be accepted in the relevant scientific communities (U.S. v. Alexander, 1975). Of particular concern to the 
judicial system is the question, "How much does forensic evidence influence a juror's decision?"

\section{Legal Precedent for Forensic Evidence}

United States (US) courts have different rules regarding the admissibility of forensic evidence. These rules regarding forensic evidence are changeable. Historically, US courts have deemed polygraph evidence, fingerprint matching, and DNA analysis both admissible and inadmissible at some point in time. For example, US courts traditionally accepted the results of a polygraph test as evidence. In the past few decades, however, courts have consistently abandoned the use of polygraph evidence. The US Supreme Court has determined that polygraph testing does not meet the Daubert standards of evidence admissibility (refer to Daubert v. Merrell Dow Pharmaceuticals, 1993). Specifically, the conclusions drawn from polygraph examiners are plagued with doubt, considered subjective, and neither verifiable nor falsifiable. Additionally, the polygraph test can be manipulated by various countermeasures (U.S. v. Scheffer, 1998).

Fingerprint matching is more readily accepted as evidence in US courts. Recently, however, several courts have ruled that the Analysis, Comparison, Evaluation, and Verification (ACE-V) method of latent fingerprint identification is unreliable (Cooper $v$. Dupnik, 1992; Maryland v. Rose, 2007; U.S. v. Plaza, Acosta, \& Rodriguez, 2002). The presiding judge in Maryland $v$. Rose noted several shortcoming of fingerprint analysis. Specifically, there is no objective criterion for determining a match, and the fingerprint analyst is not required to document the process of analysis, so there is no meaningful peer review process. Consequently, the error rate of fingerprint analysis is unknown. 
Courtroom acceptance of DNA has also changed. DNA analysis was first submitted as evidence in the mid-1980's and was accepted without challenge (Lieberman, Carrell, Miethe, \& Krauss, 2008). During that time it had been referred to as the single greatest advance in the legal system's search for truth (People v. Wesley, 1988). However, it was quickly challenged by the National Research Council of the United States of America (1992) who questioned a number of practices used by forensic scientists, which led to the improvement of validation standards set by the scientific community. Within the last decade, DNA analysis has been viewed as the most reliable form of forensic evidence (Hans, Kaye, Dann, Farley, \& Albertson, 2011; Lieberman et al.; Myers, Latter, \& Abdollahi-Arena, 2006). Despite strides in DNA analysis techniques, researchers continue to empirically investigate and question its validity and all other novel forms of forensic evidence.

\section{Jurors' Perceptions of Forensic Evidence}

In criminal trials, the prosecution and defense gather and present evidence that they believe will prove their case. In this respect, the criminal trial is an adversarial presentation of facts that may or may not convince jurors that an accused person is guilty beyond a reasonable doubt. Given the variety and complexity of forensic evidence, it is not surprising that individual jurors weigh each type of evidence differently.

Myers et al. (2006) suggests that polygraph evidence does not affect juror perceptions of guilt. Mock jurors rate the accuracy of polygraph tests between 62.0\% and 68.0\% (Myers et al., 2006). This is surprisingly low given that expert witnesses rate the accuracy of the polygraph test around $85.0 \%$ (Myers et al., 2006). In addition, Myers and Arbuthnot (1997) found no significant differences in verdicts when participants received the polygraph evidence individually or in groups. In fact, less than $2.0 \%$ of jury deliberations focused on 
the polygraph evidence. Although jurors appear to place more emphasis on other forms of forensic evidence (e.g., fingerprint matching and DNA analysis) than polygraph evidence (Myers et al., 2003; Myers et al., 2006), polygraph evidence can have an impact on the final verdict when it is coupled with corroborating evidence (e.g., medical and eyewitness testimony; Myers et al., 2003). In summation, polygraph evidence does not lead to an increase in the likelihood of a guilty verdict.

Contrary to polygraph evidence, fingerprint matching is location-based. Fingerprint matching places the defendant at the scene of the crime or ties the defendant to other physical evidence. Jurors perceive this type of evidence as more incriminating than character-based evidence (e.g., the results of a polygraph test; Myers et al., 2006). McAllister and Bregman (1986) assessed the impact fingerprint analysis has on juror perceptions of guilt by comparing it to the effects of eyewitness testimony. Participants read a trial summary involving an alleged armed robbery and murder. Participants then read that fingerprints on the gun had either been (a) positively identified as belonging to the defendant, (b) identified as not belonging to the defendant, or (c) unidentifiable. After the trial, participants rendered verdicts and rated defendant culpability on a 9-point scale. Participants rated the defendant as more guilty in the fingerprint identification condition when compared to participants in the fingerprint nonidentification and unidentifiable condition. McAllister and Bregman's research indicates that fingerprint evidence increases the likelihood that a juror will find the defendant guilty.

Contrary to polygraph evidence and fingerprint matching, DNA analysis evidence has become the revolutionary scientific tool in the search for truth (Lieberman et al., 2008). If a suspect's DNA (e.g., blood, semen, hair sample, etc.) matches DNA recovered from the 
crime scene, then it follows that the suspect was present at the crime scene. Therefore, as with fingerprint matching, DNA analysis provides attorneys with a location-based argument. However, understanding how jurors incorporate DNA evidence into their decisions is difficult because of its mathematical complexity (Koehler, 2001). Koehler demonstrated that framing DNA match statistics as probabilities (e.g., "The probability that the suspect would match the blood drops if he were not their source is $0.1 \%$ ") makes the evidence more persuasive than framing DNA match statistics in a mathematically equivalent fashion (e.g., "One in 1,000 people in Houston would also match the blood drops"). Additional research indicates that jurors are confident in the accuracy of DNA analysis evidence. On a measure of trustworthiness, Myers et al. (2006) reported that $96.0 \%$ of participants rated DNA analysis evidence as more trustworthy than polygraph evidence.

Jurors can and do understand DNA evidence (Hans et al., 2011). Potential jurors understand basic information about mitochondrial DNA (mtDNA; Hans et al.). Mitochondrial DNA is gathered from teeth, bones, and hair and is less individualizing than DNA samples from blood or semen (Hans et al.). Hans and colleagues gathered demographic information from potential jurors based on their educational background and experience with specific science courses. These participants viewed a videotaped trial summary involving an alleged armed robbery at a bank. The evidence described a lone, masked gunman in a blue sweatshirt who fled the crime scene. While in pursuit, local police found the suspect's discarded hooded sweatshirt and the stolen currency. Laboratory examination of the sweatshirt revealed two hairs which were sent to an FBI crime laboratory for investigation. In addition, the summary included the defendant's reference to a half-brother who lived in the area. The half-brother had the same father but not the same mother and acted as a "red 
herring" because the half-brother would not share the same mtDNA sequence given that he had a different mother. Two experts talked about maternal inheritance but were not questioned about it. This evidence was included to see if mock jurors could be lured into believing the half-brother was the source of the mtDNA (Hans et al.).

After viewing the trial summary, participants were tested on their knowledge of mtDNA evidence. When asked, "In your own words, what is mitochondrial DNA (mtDNA) evidence?" $80.0 \%$ of participants made at least one correct statement, whereas only $20.0 \%$ made an incorrect statement. Also, juror comprehension was positively related to the number of math and science courses jurors had completed. Lastly, the reference to the half-brother did not appear to confuse jurors, as $84.0 \%$ correctly noted that mtDNA does not come from both the mother and father. These results indicate that jurors generally understand forensic evidence and are able to incorporate it into their decisions.

\section{Magnetic Resonance Imaging-Based Evidence}

MRI is a medical imaging technique commonly used in radiology. It allows researchers to visualize detailed internal structures (e.g., the brain, muscles, the heart, and various cancers) through the process of nuclear magnetic resonance (Qian \& Wei, 2012). This technology is not to be confused with functional magnetic resonance imaging. Functional MRI is a noninvasive neuroimaging technique that identifies active areas of the brain by measuring oxygenated blood flow to areas of cortical activity (Bhatt et al., 2009). Functional MRI is used to map areas of the brain that require more oxygen during behavioral tasks, but can also be used to demonstrate brain abnormality and to detect whether someone is telling a lie (Bhatt et al.; Davatzikos et al., 2005). A simple method of understanding the 
difference between the imaging technologies is to consider that MRI represents brain structure while fMRI represents brain function.

Researchers have empirically established a link between criminal and violent behavior and brain structure using MRI (see Mobbs, Lau, Jones, \& Frith, 2007; Raine, 2008, for reviews). However, it is important to note that while MRIs are common medical procedures, scientists do not agree on what, if anything, MRI techniques and its neuroscience-based derivatives (i.e., functional magnetic resonance imaging) tell us about human behavior (Aue, Lavelle, \& Cacioppo, 2009; Heeger \& Ress, 2002). Consequently, judges and legal scholars have raised concerns about the conclusions drawn from neuroscience-based evidence (Dresser, 2010). Regardless of concerns, neuroscience-based evidence is now on the precipice of being allowed as a form of forensic evidence in US courts.

To date, MRI evidence use has been documented in two cases. One US court has allowed MRI evidence that links brain abnormality to individual behavior. In this court, MRI evidence was used as mitigating evidence during the sentencing phase of a death penalty case heard in Chicago, Illinois (Madrigal, 2009; Saenz, 2009). The defense argued that the defendant should not be put to death because the MRI evidence suggested that the defendant had an abnormal brain. The decision to allow MRI evidence to be presented at trial may reflect the legal system's view that death is a serious, irreversible form of punishment. The legal rules that govern the death penalty aim to ensure extraordinary procedural safeguards (Vidmar \& Hans, 2007). The other documented use of MRI evidence was in Roper v. Simmons (2005). The Supreme Court received an amicus brief from the Coalition for Juvenile Justice (CJJ) suggesting that adolescent brains are not fully formed which 
contributes to an increase in impulsivity and mood swings in adolescents (Brief of the CJJ, 2005). It was unclear whether the Supreme Court used the evidence in its decision because the Court did not mention the evidence in its written conclusion (Madrigal).

Currently, only one study has examined the impact MRI-based evidence has on juror perceptions of guilt (McCabe et al., 2011). This experiment used functional MRI (fMRI), a similarly noninvasive technique that allows scientists to observe the results of an MRI scan over time during a behavioral task (e.g., lying; Bhatt et al., 2009). Participants who read a trial summary with fMRI lie detection evidence rendered more guilty verdicts than participants who read the same trial summary with polygraph evidence, thermal imaging (i.e., another novel form of lie detection), or no lie detection evidence. Neither MRI nor fMRI have been extensively researched in juror decision-making studies.

To address this lack of research, the present study uses MRI to suggest [emphasis added] that the defendant had characteristics of psychopathy. These characteristics include an unusually high tendency to act impulsively without thinking and an increased tendency to take risks and seek thrills (see Appendix B, paragraphs 10 and 11; McCabe et al., 2011). The MRI expert in this trial did not use the word psychopath to describe the defendant. This argument is loosely character-based (i.e., the defendant has behavioral problems) and does not make a connection between psychopathy and criminality.

Previous research indicates that providing brain-related information to participants may unduly influence how participants assess scientific data. One study gave neuroscience experts, students in a neuroscience course, and laypersons a brief description of a psychological phenomenon (Weisberg, Keil, Goodstein, Rawson, \& Gray, 2009). They were also given an explanation for the phenomenon that was manipulated (high quality vs. low 
quality) along with the content of explanation (with neuroscience vs. without neuroscience). All neuroscientific explanations were irrelevant to the psychological phenomenon. Participants from all three groups rated high quality explanations as more satisfying than low quality explanations. Participants also rated explanations with neuroscience information as more satisfying than explanations without neuroscience information. Moreover, student and laypersons, compared to neuroscience experts, rated explanations with logically irrelevant neuroscience information as more satisfying than explanations without neuroscience information.

MRI evidence with brain images may be particularly damaging to a defendant. McCabe and Castel (2008) claim that the fascination with and the perceived credibility of neuroimaging lies in the persuasive power of the images themselves. McCabe and Castel demonstrated this persuasive power by creating mock scientific articles (e.g., "Watching TV is related to math ability"). In their mock article, it is suggested that both watching TV and performing math problems increase frontal lobe activation, therefore watching TV improves math ability. McCabe and Castel asked participants to read mock articles that varied by the presence vs. absence of brain images. Participants who read the article and were presented with accompanying brain images rated the claim as more valid than participants who only read the article.

The difference between MRI evidence with and without brain images is an important distinction. Links between criminal and violent behavior and brain structure have been empirically established (Mobbs et al., 2007; Raine, 2008). Thus the image is an integral part of the MRI results. This image, however, would be subject to rules 403 and 702 of the Federal Rules of Evidence (Cornell University Law School, 2010). Rule 403 states that 
relevant evidence may be excluded if it creates unfair prejudice, confusion of the issues, a waste of time, or misleads the jury. Rule 702 suggests that an expert witness may testify if the testimony is based on sufficient facts or data, is the product of reliable methodology, and the witness has applied the methodology to the facts of the case. An image, however, may be excluded if it violates the Federal Rules of Evidence. It is not clear whether neuroimages create unfair prejudice, although previous research indicates that neuroscience explanations were rated as more valid with neuroimages than without (McCabe \& Castel, 2008). Thus, it is possible that the images submitted along with MRI evidence may create unfair prejudice. In addition to being underused in the legal system, the effect of MRI evidence on jurors' perceptions of defendant guilt has not been thoroughly researched in the field of psychology.

\section{Present Study}

The present study was designed to determine if MRI influences jurors' perceptions of guilt. The trial summary involved behaviors related to psychopathy. Research has demonstrated that there are structural brain differences between diagnosed psychopaths and control subjects without psychopathy (Gao, Raine, \& Phil, 2010). The MRI evidence suggested [emphasis added] that the defendant has psychopathic tendencies, which creates a link between the brain structure and the murderous behavior.

Participants assessed defendant guilt based on evidence presented in a written trial summary. The summaries included 22-24 points of evidence and differed in only one aspect: one-third of the trial summaries included MRI evidence with brain images, one-third included MRI evidence without images, and one-third did not include MRI evidence. Participants also completed a post-trial questionnaire that assessed both juror perceptions of guilt and the influence and accuracy of the evidence presented. 
Based on previous research involving brain images and fMRI evidence (McCabe et al., 2011; Weisberg et al., 2009), it was hypothesized that: (1) both MRI conditions would lead to more guilty verdicts than the control condition; (2) the MRI evidence condition with brain images would lead to more guilty verdicts than both the MRI condition without brain images and the control condition; and (3) the part of the trial summary that includes MRI evidence would be listed as the most influential piece of evidence.

\section{Method}

\section{Participants}

Data was collected from 119 psychology undergraduates, who had not yet taken courses in cognition or behavioral neuroscience, from Western Washington University. Participants volunteered to participate in a study involving juror decision making via Sona Systems. Ten participants were removed from the analyses for marking "no" to the question “Are you a U.S. citizen?” The remaining 109 participates (51 male, 58 female) were jury eligible (i.e., U.S. citizens over the age of 18 years of age). The mean age of the overall sample was $19.34(S D=1.95)$. Participants received course credit for approximately 30 minutes of participation.

\section{Design}

Experimental sessions, rather than participants, were randomly assigned to one of three conditions. The independent variable was MRI evidence presented in a trial summary. MRI evidence was (1) presented with corresponding brain images (MRI + Images), (2) presented without brain images (MRI), or (3) not presented (control).

The primary dependent variables were (1) verdict (guilty vs. not guilty), (2) ratings for likelihood of defendant guilt and participant confidence in his/her verdict, (3) selection of 
one piece of evidence that was most influential to the decision, and (4) a rating of how influential this evidence was in rendering the final verdict. Influence and accuracy ratings of all testimony presented were also assessed.

\section{Procedure}

After providing informed consent, participants were given a packet containing a pretrial demographic questionnaire, a trial summary, and a post-trial questionnaire. The entire packet was completed and returned into the experimenter. Participants were then given an additional multiple-choice manipulation check questionnaire to assess whether they had read and understood the trial summary. After completing the manipulation check items and returning it to the experimenter, participants were thanked, given a one-page debriefing form, and then dismissed.

\section{Materials}

Trial summary. The trial summary was adapted from the trial, State v. Givens, created by Kassin and Sommers (1997) and used by McCabe et al. (2011). In this trial, the defendant, Brad Givens, is charged with murdering his estranged wife and her lover. The prosecution claims that the defendant murdered the couple in a jealous rage, while the defense maintains the Givens found the bodies when he returned home to retrieve personal papers. The trial summary is three pages long (i.e., 22 paragraphs). It includes opening and closing statements, the examination and cross-examination of six witnesses (a private investigator, police officer, coroner, eyewitness, the defendant, and a friend of the defendant), and the judge's instructions. A number was placed next to each paragraph and served as an aid for the posttrial questionnaire. The summary was designed to be "circumstantial, incomplete, and 
ambiguous" (Kassin \& Sommers, pp.1048) to ensure that the inclusion of the MRI evidence would influence the verdict.

MRI conditions. Both MRI conditions (MRI + Images and MRI) included two paragraphs of testimony from Dr. Ronald Tinsworth, a psychiatrist. The information presented in the MRI conditions was held constant; the only difference between the two conditions was the absence vs. presence of MRI images. The name of the defendant and the content of Dr. Tinsworth's testimony were adapted to match the language used in State v. Givens.

In his testimony, Dr. Ronald Tinsworth presented the results of a personality evaluation and scans from the defendant's brain using MRI. The personality evaluation measured psychopathic tendencies (e.g., tendency to act impulsively without thinking and tendency to take risks and seek thrills), though Dr. Tinsworth never stated that the defendant is psychopathic. Dr. Tinsworth explained that, according to the personality evaluation, the defendant has "an unusually high tendency to act impulsively without thinking and to take risks and seek thrills (Appendix B, paragraph 10).” His assessment was corroborated by the results of the MRI. Dr. Tinsworth noted that the MRI showed reduced gray matter density in the left middle frontal gyrus and left superior frontal gyrus of the defendant's brain when compared to normal individuals; thus, the MRI suggested that the defendant not only has poor inhibitory control, but also has issues with impulsivity. Dr. Tinsworth concludes that his results have been replicated in the scientific community. During his cross-examination, Dr. Ronald Tinsworth concedes that "MRI is a useful medical and diagnostic tool, [though the results] are not conclusive of impulsive tendencies and poor inhibitory control specific to the 
results of personality evaluations (Appendix B, paragraph 11)." Tinsworth further concedes that the results of MRI are contested in the scientific community.

The MRI + Images condition included brain images adapted from Rigoni et al. (2010). These brain images are from the brain of an actual young woman tried for violent murder. This woman underwent psychiatric evaluation using Lilienfeld and Widows' (2005) Psychopathic Personality Inventory-Revisited (PPI-R; as cited in Rigoni et al.). Rigoni et al. also obtained an MRI scan of her brain relative to six healthy control participants. The MRI scan in the Rigoni et al. study showed reduced gray matter density in the left superior frontal gyrus and the left middle frontal gyrus of the woman's brain when compared to healthy control participants. Her red areas indicate areas of the brain that are lacking gray matter density. For the purpose of the present study, the woman's images were used to represent the defendant's brain function (see Figure 1 and Figure 2 of Appendix $C$ for the experimental adaptations).

Pre-trial questionnaire. The pre-trial questionnaire assessed the participant's sex, age, year in school, citizenship status, and prior jury experience (see Appendix A).

Post-trial questionnaire. The post-trial questionnaire assessed verdict preference and perceptions of the evidence.

Verdict preference was defined by an assessment of guilt (guilty vs. not guilty), a likelihood of guilt rating ranging from 1 (not at all likely) to 6 (very likely), and a confidence in verdict rating ranging from 1 (not at all confident) to 6 (very confident). Perception of the evidence was defined by (1) a participant's selection of the most influential piece of evidence, (2) a rating of how influential it was in rendering the final verdict ranging from 1 (not at all influential) to 6 (very influential), (3) ratings of the overall influence of the 
prosecution and defense ranging from 1 (not at all influential) to 6 (very influential), and (4) ratings of influence and accuracy from every witness testimony ranging from 1 (not at all influential/accurate) to 6 (very influential/accurate; see Appendix D).

Manipulation check questionnaire. The manipulation check questionnaire included up to seven multiple-choice questions that assessed the participants' memory for specific details of the case. Four of the questions assessed memory for specific facts of the case (e.g., "What was the alleged murder weapon?" and "What is the name of the defendant in the trial?"). These four questions were presented in every condition. Three additional questions assessed how well participants understood the MRI evidence (see Appendix E). Note that the MRI questions were specific to conditions that included MRI evidence.

\section{Results}

\section{Randomization Checks}

A chi-square test of independence was conducted to determine if the distributions of participant sex, prior jury experience, and year in school were similar across conditions. Nonsignificant differences across conditions indicate that participant $\operatorname{sex}\left(\chi^{2}(2, N=109)=3.06, p\right.$ $=.217$, Cramér's $V=.17)$, prior jury experience $\left(\chi^{2}(2, N=109)=2.05, p=.359\right.$, Cramér's $V$ $=.14)$, and year in school $\left(\chi^{2}(2, N=109)=8.70, p=.191\right.$, Cramér's $\left.V=.20\right)$ were evenly distributed across conditions. A one-way, between-subjects ANOVA was conducted to determine if participant age varied across conditions. Age was evenly distributed across conditions, $F(2,106)=2.77, p=.067, \eta^{2}=.05$.

\section{Verdict Preference}

Table 1 shows the proportion of guilty verdicts for each condition. In order to test Hypotheses 1 and 2, a chi-square test of independence was conducted to determine if the 
proportion of guilty verdicts differed by condition. The chi-square test of independence indicated that the proportion of guilty verdicts was not influenced by MRI testimony nor MRI testimony that included images $\left(\chi^{2}(2, N=109)=1.90, p=.388\right.$, Cramér's $\left.V=.13\right)$.

One-way, between-subjects ANOVAs were conducted to determine if the likelihood of guilt and confidence in verdict ratings differed by condition. Participant ratings of the likelihood of guilt did not differ by condition $\left(F(2,106)=2.43, p=.093, \eta^{2}=.04\right)$, nor did participant ratings of confidence in verdict $\left(F(2,106)=0.69, p=.504, \eta^{2}=.01\right)$. Thus, Hypotheses 1 and 2 were not confirmed. See Table 2 for mean ratings of guilt and confidence by condition.

\section{Perceptions of MRI Evidence}

In order to test Hypothesis 3, participants were asked to list the piece of evidence most influential to their verdict (Appendix D, question 4). Hypothesis 3 predicted that MRI evidence would be listed as the most influential piece of information presented in the trial summary.

Contrary to Hypothesis 3, the closing statement of the defense attorney (paragraph 23 ), the closing statement of the prosecuting attorney (paragraph 21), and the crossexamination of the defendant (paragraph 19) were selected by the most participants. Paragraph 23 was selected by $30.8 \%$ of the participants, and all of the participants who selected it rendered not guilty verdicts. Paragraph 21 was selected by $16.8 \%$ of the participants and almost all (94.4\%) of the participants who selected it rendered guilty verdicts. Paragraph 19 was selected by $13.1 \%$ of the participants, and all of the participants who selected it rendered guilty verdicts. The remaining pieces of evidence were selected by $4.7 \%$ or fewer participants. A chi-square test of independence (using only participants who 
listed paragraph 19,21 , or 23 ) was conducted to determine if participant selections of the most influential piece of evidence differed across conditions. Selection of paragraphs 19, 21, and 23 did not differ significantly by condition, $\chi^{2}(4, N=65)=3.91, p=.419$, Cramér's $V=$ .17 .

Participant ratings of MRI expert influence, MRI expert accuracy, and MRI procedure accuracy were analyzed to better understand the probative value of MRI evidence. The results indicated that participants were not that influenced by the testimony of the MRI expert $(M=2.96, S D=1.36)$. Participants did, however, perceive the testimony of the MRI expert as somewhat accurate $(M=3.99, S D=1.09)$. The MRI procedure itself was also perceived as being somewhat accurate $(M=3.46, S D=1.45)$. An independent-sample T test was conducted to determine if influence and accuracy ratings of the expert's testimony differed as a result of the MRI images. The expert's testimony was more influential in the MRI condition $(M=3.39, S D=1.34)$ than the MRI + Images condition $(M=2.53, S D=$ $1.25 ; t(70)=2.82, p=.006, d=0.66)$. However, the expert's testimony did not differ in ratings of accuracy between conditions $(t(70)=1.19, p=.239, d=0.28)$. Additionally, perceptions of the accuracy of the MRI procedure did not differ between conditions $(t(70)=$ $.89, p=.376, d=0.21)$.

\section{Perceptions of Trial Evidence}

No hypotheses were generated for the other forms of trial evidence. Separate oneway, between-subjects ANOVAs were conducted to determine any differences for the following conditions: (1) participant ratings of the overall case presented by the prosecution; (2) participant ratings of the overall case presented by the defense; (3) participant ratings of influence and accuracy for the testimonies of the private investigator, police officer, coroner, 
eyewitness, friend of the defendant, and the defendant himself. No significant findings emerged (all $p$ 's $>.05)$.

\section{Manipulation Check}

The manipulation check assessed participant knowledge of general case facts and the MRI evidence. A one-way, between-subjects ANOVA was conducted to determine if participant recall of trial facts differed by trial condition. Each of four general case facts were dummy coded so that $1=$ correct and $0=$ incorrect. Participant recall was assessed by creating a separate variable equal to the total number of correct responses for each participant (i.e., between 0 and 4). Participant recall did not differ by condition, $F(2,106)=.12, p=$ $.885, \eta^{2}=.00$. Participants recalled almost all four facts of the case $(M=3.94, S D=.28)$. This indicated that participants read and understood the trial summary. Table 3 shows the percent of correct responses to each general knowledge item.

An independent-sample $\mathrm{T}$ test was conducted to determine if participants responses to MRI specific questions varied by trial condition. Participants in the control condition were not included in this analysis because they did not receive any MRI specific questions. Each of three MRI questions were dummy coded such that $1=$ correct and $0=$ incorrect. Participant performance was assessed by creating a separate variable equal to the total number of correct responses for each participant (i.e., between 0 and 3). Participant performance on the MRI specific questions did not differ by condition, $t(71)=-.25, p=.801$, $d=0.06$. Across both MRI conditions participants answered approximately half of the questions correctly $(M=1.86, S D=.86)$. Table 4 shows the percent of correct responses to each MRI manipulation check question. Overall, $57.5 \%$ correctly answered the question about the defendant's specific behavioral problems, 39.7\% correctly answered the question 
about what MRI can conclusively demonstrate, and $89.0 \%$ correctly answered the question about what the MRI did demonstrate, suggesting there may have been some confusion regarding the MRI expert's testimony.

\section{Discussion}

The current study investigated the influence of neuroimaging evidence on juror perceptions of guilt. Contrary to all three proposed hypotheses, MRI may not influence juror perceptions of guilt. Specifically, the MRI evidence did not affect guilty verdicts rendered by jurors (Hypothesis 1 and 2), nor was the MRI evidence selected as the most influential piece of evidence (Hypothesis 3).

Results from the present study were largely inconsistent with previous research (McCabe et al., 2011). In McCabe et al., jurors rendered more guilty verdicts when presented with fMRI-based methods of lie detection evidence than with polygraph, thermal imaging, or no lie detection evidence. This effect was attributed to an explicit link between biology and behavior, suggesting that a biological basis for a defendant's criminal behavior increases jurors perceptions' of guilt. Based on the study by McCabe et al., it would appear that evidence of lying is more compelling when it is accompanied by evidence that was obtained directly from the brain (McCabe et al.). However, results from the present study did not show an increase in guilty verdicts in the MRI evidence conditions.

The present study's results, however, are reconcilable with patterns found in McCabe et al. (2011). McCabe et al. included a validity questioned condition in which the fMRI expert admitted during his testimony that the conclusions drawn from fMRI images have been wrong in several cases. Guilty verdicts in the validity questioned condition and control condition were equivalent, suggesting that jurors become skeptical of the procedure and 
found the evidence less persuasive when the procedure was called into question. The present study also provided participants with evidence obtained directly from the brain. However, the validity of the MRI procedure was called into question through the cross-examination of the MRI expert in both MRI conditions. In this respect, all MRI conditions were validity questioned conditions, and none of the conditions isolated the effect of the MRI evidence without questioning the validity of the scientific procedure. Thus, one explanation for the null results in this study is that the effect of neuroimaging technology may have been reduced and/or eliminated when the validity of the procedure was called into question during crossexamination, as it was in the McCabe et al. study.

The null results could also be the result of poor understanding of the MRI evidence. Specifically, question 2 ("Dr. Ronald Tinsworth concluded that Givens had all of the following behavioral tendencies except?") was answered correctly by only $57.5 \%$ of the participants. Several possibilities exist that explain this poor level of performance. It is possible participants were distracted by the term "except". "Except" questions require the reader to select an answer that is incorrect. The word was italicized and underlined to draw attention to the word and prevent confusion. Another possibility for poor participant performance is answer similarity. Answers $\mathrm{a}, \mathrm{b}$, and $\mathrm{c}$ were all mentioned in the same sentence during Tinsworth's testimony: “[He] claims that Givens has an unusually high tendency to act impulsively without thinking and to take risks and seek thrills." Answer d ("Tendency to anger easily"), however, is a behavioral tendency one can still associate with a defendant who has been charged with first degree murder. Lastly, the sentence does not take long to read. It is possible that the information may have been glossed over by the participants. Next, question 5 ("MRI can conclusively demonstrate which of the following?") 
was answered correctly by only $39.7 \%$ of the participants. The question was designed to test whether the participants understood that MRI evidence does not conclusively demonstrate any link between brain and behavior. Answer b, "Individuals with reduced gray matter are more impulsive," was selected by $95.5 \%$ of the participants who missed the question.

Reduced gray matter and impulsivity were a part of Tinsworth's original testimony; however, answer $b$ is incorrect because Tinsworth conceded that the results of the MRI are not conclusive of impulsive tendencies or poor inhibitory control during his cross-examination. It is likely the participants who selected answer b were unable to distinguish between Dr. Tinsworth's original testimony and his cross-examination.

The present study found that neuroimages do not create unfair prejudice. This finding is inconsistent with previous research (McCabe \& Castel, 2008). Neuroimages were expected to increase the impact of the MRI evidence. One explanation for this null finding is that the MRI evidence was not useful to participants in their verdict decisions. This explanation is supported by the fact that only $5.6 \%$ of participants selected the MRI evidence as the most influential piece of evidence presented in the trial summary. If the MRI evidence was not useful in rendering a verdict, then the additional MRI images would have also been irrelevant to the process of rendering a verdict. Another explanation could be a "trying too hard" effect in which participants feel the prosecution is using the neuroimages to fill in the holes of an incomplete and circumstantial case. If this were true, then participants may have believed the neuroimages were presented to cover up the fact the prosecution did not have other forms of evidence (i.e., DNA or fingerprints) linking the defendant to the crime.

Inconsistent results may also be attributed to the testimony of the expert witness, Dr. Ronald Tinsworth. Firstly, prior research indicates that expert witness credibility is important 
(Horowitz et al., 2001) and that the general public is unaware of what a psychiatrist does (Williams, Cheyne, \& MacDonald, 2001). In Williams et al., half of the sample did not know that psychiatrists were medically qualified, and $80 \%$ underestimated the length of psychiatric training. The present study did not modify Tinsworth's credibility. Without modifying the credentials of the expert, it is impossible to determine if a neurologist using MRI would have had more influence on juror perceptions of guilt than the psychiatrist. Secondly, Tinsworth did not educate jurors on the importance of the images, nor did he explain in any detail what gray matter is or what its function is in the human brain. Kovera and colleagues (1997) determined that the experts' attempts to educate jurors influence their decision making processes. A more informed jury may have rendered a different verdict.

A simpler explanation for the results may be that functional MRI evidence is not the same as MRI evidence. The null results could potentially reflect differences in the technology or differences in the application of the technology (i.e., structure vs. function). Functional MRI evidence was used in McCabe et al. (2011) to demonstrate that the defendant lied about killing his wife. In this instance, fMRI captured the activity of lying in an image. Conversely, the present study used MRI to image the structure of the defendant's brain. The resulting image was used to imply that the defendant has an abnormal brain resulting in behavioral deficits. Both the McCabe et al. and the present study adapted their trial summaries from the Kassin and Sommers (1997) study. The key difference between these two studies was the type of evidence (MRI versus fMRI) and not the trial summaries.

These explanations aside, it can be concluded the null results related to Hypotheses 1 and 2 are not due to a lack of randomization, ceiling or floor effects, nor a lack of statistical power. Specifically, the randomization checks showed that participant age, sex, juror 
experience, and year in school were successfully distributed across conditions. In addition, participants were only moderately sure the defendant was guilty $(M=4.11, S D=.98)$ and moderately confident in their verdict $(M=4.18, S D=1.04)$. The means and standard deviations of the likelihood of defendant guilt and verdict confidence ratings suggest that any change in these dependent measures, due to an effect of the independent variable, could have been detected. Thus, both ceiling and floor effects were avoided. Lastly, a power analysis was conducted to determine if there was sufficient power to detect the effect sought. The sample $(\mathrm{N}=119)$ was large enough to detect medium effect sizes with sufficient power (i.e., 80) at $\alpha=.05$ (Cohen, 1992).

Contrary to Hypothesis 3, less than $6.0 \%$ of the participants selected the MRI expert's testimony as the most influential piece of evidence. Although the low selection rate indicates that participants did not view the MRI evidence as the most influential piece of evidence, it does not indicate how participants utilize the MRI evidence in their decision-making process. It may be that, in the circumstances of this case, one point of evidence is not as influential as the entire case for or against the defendant. Thus, the null results for Hypothesis 3 may have been made possible by allowing participants to select the closing arguments. The closing statement of the defense attorney (paragraph 23) was the most influential piece of evidence followed by the closing statement of the prosecuting attorney (paragraph 21). The closing arguments represent the collective weight of all pieces of evidence rather than one isolated piece of evidence.

Lastly, participant ratings of the accuracy of MRI evidence (both expert testimony and the procedure itself) suggest the inclusion of MRI images does not affect perceptions of accuracy. However, participants rated the MRI expert's testimony as more influential in the 
MRI condition than the MRI + Images condition. This finding is inconsistent with research that suggests neuroimages increase ratings of validity (McCabe \& Castel, 2008). One of four explanations may account for this inconsistency. One, participants may have realized that the neuroimages were unnecessary because the MRI expert adequately explained the tests he ran on the defendant. Two, participants may have picked up on the experimental manipulation as the neuroimages were separately attached to the trial summary. However, this explanation is unlikely because experimental sessions, rather than participants, were randomly assigned to conditions. Participants would not know other groups received different evidence.

Additionally, with only one former juror as a participant, participants would not know that attaching neuroimages during a legal proceeding is a controversial topic (Rosen, 2007). Three, participants may not have understood the MRI evidence. If this were true, then participants would not find the inclusion of the images useful. This explanation is supported by poor participant performance on two of the three MRI manipulation checks. Lastly, the finding that MRI evidence without images was more influential than MRI evidence with may be an artifact of $p<.05$. All other statistical analyses yielded non-significant results. This result may have been obtained by chance.

\section{Limitations}

The conclusions drawn from this data must also be considered in the context of several potential methodological limitations. First, the trial summary was short. Participants had a half hour to read, comprehend, and evaluate the evidence for a trial intentionally designed to be circumstantial and ambiguous. Additionally, each witness's testimony was approximately one paragraph in length. Although the use of trial summaries is typical in jury research, this form of evidence presentation does not generalize well when compared with 
the experience of an actual juror (Kessler, 1975). In addition, this methodological choice allows participants to base decisions on a small fraction of the potential information that would be available during an actual trial. This may account for why participants indicated that the summary paragraphs by the defense and prosecution were most influential.

Second, this study uses a student sample rather than a community sample. Students, although jury eligible, are not the only members of a community eligible for jury duty. Some researchers have argued that decisions rendered by WEIRD (western, educated, industrialized, rich, and democratic) college students may not be representative of those rendered by actual jurors (Henrich, Heine, \& Norenzayan, 2010). Other researchers have found no difference in juror decisions rendered by students and community samples (Devenport \& Cutler, 2004; Devenport, Stinson, Cutler, \& Kravitz, 2002; Myers et al., 2003; Myers et al., 2006). The present study did exclude all participants who were not jury eligible. It is believed that this sample did not negatively influence the results because both students and laypersons have limited exposure to neuroscience information (Weisberg et al., 2009).

Third, this study did not include a deliberation process. Jury deliberations are underrepresented in juror research (Bornstein \& McCabe, 2005) primarily due to time and money constraints (Studebaker et al., 2002). The exclusion of a deliberation limits the external validity of the present study, as some critics have argued that an individual decision is not the same as a decision reached through deliberation (Devine, Clayton, Dunford, Seying, \& Pryce, 2001). This argument is predicated on the notion that deliberation has the ability to change individual juror decisions. A meta-analysis on jury deliberations provided the argument that, in one out of ten trials, deliberations resulted in a reversal of the verdict 
preference originally favored by the majority (Devine et al.). It is unclear whether a deliberation would have changed the results of the present study.

Finally, this study was a simulation. Participants were invited into a classroom, asked to read a brief summary of a trial, and given course credit for their participation. Simulation methodology raises the question "Are the participants motivated to render a just decision?" Some critics argue that simulations do not reflect the real-world consequences of an actual trial and thus mock-jurors' may not be motivated to thoroughly process the evidence and render thoughtful verdict decisions in a trial simulation (Bornstein \& McCabe, 2005). For example, pre-deliberation questionnaires indicate that actual jurors believe their verdicts have consequences for the defendant and feel that their decisions are significantly more important than those of mock jurors (Bornstein \& McCabe). Other researchers, however, have found that the artificial nature of a simulation does not affect participant motivation or verdict preference (Kerr, Nerenz, \& Herrick, 1979; MacCoun \& Kerr, 1988). Critiques of simulation based research are accepted and encouraged for the scientific advancement of knowledge and understanding. It must be understood, however, that jury research using simulated trials is the norm in the relevant scientific community (e.g., refer to the reference section of Bornstein and McCabe for a variety of studies using simulation-based methodologies). Given the status of the simulation-based research debate, it is unclear how the artificial nature of the experiment affected the results.

\section{Implications for Future Research}

The present study would suggest several directions for future research. One recommendation involves further investigation of the effect of neuroimages on juror decision making. The present study manipulated the presence vs. absence of neuroimages. However, 
several aspects of the neuroimages have yet to be researched. Future studies should have participants rate the relevance of the neuroimages, making it possible to analyze the impact the image itself has on individual jurors perceptions' of defendant culpability. Additionally, the neuroimages of the defendant can be visually compared to the images of normal (emphasis added) individuals. Neuroimages have been introduced as evidence in court (Madrigal, 2009). Also consider the severity of the brain damage represented in the images. The present study presented a brain with reduced gray matter in the left middle frontal gyrus and left superior frontal gyrus. A lesion or tumor in these areas, for example, may elicit a different response from jurors. These modifications are important first steps to understanding the influence those images have on juror perceptions of guilt.

Another recommendation involves the cross-examination of the MRI expert about the validity of the MRI procedure. An opposing attorney, in an actual trial, may or may not question the validity of the MRI procedure. How an attorney cross-examines a witness depends on several factors not addressed in this study (e.g., the quality of the attorney, the attorney's knowledge of MRI, etc.). The present study is only generalizable to court cases in which an attorney questions the validity of the MRI procedure. Our understanding of a "validity questioned" effect can be enhanced by a study that manipulates the forensic evidence presented at trial separately from whether the validity of the forensic evidence is called into question. This will allow researchers to generalize to trials that do and do not question the validity of a scientific procedure. Furthermore, the way in which the attorney questions the validity of the forensic procedure during cross-examination should also be examined, as some types of questioning strategies may be more or less effective than others. 
Furthermore, future studies should address how and why forensic evidence is influential. In the current study, participants were asked to select the paragraph that was most influential to their verdict. Unfortunately, a majority of participants selected the closing arguments as the most influential piece of evidence. By selecting a closing argument, a participant is indicating that all [emphasis added] evidence is required to render a verdict. Future studies should exclude the closing arguments as evidence that may be selected and require participants to select only individual pieces of evidence. The selection of a single piece of evidence better indicates what evidence jurors find influential. Additionally, participants could rank the five most influential pieces of evidence. This serves the purpose of providing researchers with a basic hierarchy of what evidence carries the most probative weight. Conversely, participants could rate the influence and importance of every individual piece of evidence. This enables a researcher to quantitatively observe and statistically test the influence of the experimental manipulation as well as the other evidence presented during the trial.

Finally, an open-ended, free-response question could provide a qualitatively rich explanation of jurors' perceptions of the evidence (refer to the Hans et al., 2011 methodology). Qualitative assessment helps researchers establish theories for how and why evidence is influential. In essence, free-response questions provide a considerable amount of data that can be useful for developing hypotheses. This approach is one of the best ways to determine what questions future studies in the field should address. 


\section{References}

Aue, T., Lavelle, L. A., \& Cacioppo, J. T. (2009). Great expectations: What can fMRI research tell us about psychological phenomena? International Journal of Psychophysiology, 1-7. doi:10.1016/j.ijpsycho.2008.12.017

Bhatt, S., Mbwana, J., Adeyemo, A., Sawyer, A., Hailu, A., \& VanMeter, J. (2009). Lying about facial recognition: An fMRI study. Brain and Cognition, 69, 382-390. doi:10.1016/j.bandc.2008.08.033

Bornstein, B. H., \& McCabe, S. G. (2005) Jurors of the absurd? The role of consequentiality in jury simulation research. Florida State University Law Review, 32, 443-467. Brief of the Coalition for Juvenile Justice as Amici Curiae in Support of Respondent, Roper v. Simmons, 543 U.S. 551 (2005).

Cohen, J. (1992). A power primer. Psychological Bulletin, 112, 155-159.

Cornell University Law School (2010). Federal Rules of Evidence, Retrieved May 1, 2012 from http://www.law.cornell.edu/rules/fre

Cooper v. Dupnik, 963 F. 2d 1220 (9th Cir. 1992).

Daubert v. Merrell Dow Pharmaceuticals, 509 U.S. 579 (1993).

Davatzikos, C., Ruparel, K., Fan, Y., Shen, D. G., Acharyya, M., Loughead, J. W.,...Langleben, D. D. (2005). Classifying spatial patterns of brain activity with machine learning methods: Application to lie detection. NeuroImage, 28(3), 663-668. doi:10.1016/j.neuroimage.2005.08.009

Devenport, J. L., \& Cutler, B. L. (2004). Impact of defense-only and opposing eyewitness experts on juror judgments. Law and Human Behavior, 28, 569-576.

doi:10.1023/B:LAHU.0000046434.39181.07 
Devenport, J. L., Stinson, V., Cutler, B. L., \& Kravitz, D. A. (2002). How effective are the cross-examination and expert testimony safeguards? Jurors' perceptions of the suggestiveness and fairness of biased lineup procedures. Journal of Applied Psychology, 87, 1042-1054. doi:10.1037//0021-9010.87.6.1042

Devine, D. J., Clayton, L. D., Dunford, B. B., Seying, R., \& Pryce, J. (2001). Jury decision making: 45 years of empirical research on deliberation groups. Psychology, Public Policy, and Law, 7, 622-727.

Dresser, R. (2010). Brain imaging and courtroom deception. Hastings Center Report, 40, 7-8. Retrieved from http://papers.ssrn.com/sol3/papers.cfm?abstract_id=1763304

Gao, Y., Raine, A., \& Phil, D. (2010). Successful and unsuccessful psychopaths: A neurobiological model. Behavioral Sciences and the Law, 28, 194-210. doi:10.1002/bsl.924

Hans, V. P., Kaye, D. H., Dann, B. M., Farley, E. J., \& Albertson, S. (2011). Science in the jury box: Juror's comprehension of mitochondrial DNA evidence. Law and Human Behavior, 35, 60-71. doi:10.1007/s10979-010-9222-8

Heeger, D. J., \& Ress, D. (2002). What does fMRI tell us about neuronal activity? Nature Reviews, 3, 142-151. doi:10.1038/nrn730

Henrich, J., Heine, S. J., \& Norenzayan, A. (2010). The weirdest people in the world? Behavioral and Brain Sciences, 33, 61-135. doi:10.1017/S0140525X0999152X

Horowitz, I. A., Bordens, K. S., Victor, E., Bourgeois, M. J., \& ForsterLee, L. (2001). The effects of complexity on jurors' verdicts and construction of evidence. Journal of Applied Psychology, 86, 641-652. doi:10.1037/0021-9010.86.4.641 
Kassin, S. M., \& Sommers, S. R. (1997). Inadmissible testimony, instructions to disregard, and the jury: Substantive versus procedural considerations. Personality and Social Bulletin, 23, 1046-1054. doi:10.1177/01461672972310005

Kerr, N. L., Nerenz, D., \& Herrick, D. (1979). Role playing and the study of jury behavior. Social Methods and Research, 7, 337-355. doi:10.1177/004912417900700305

Kessler, J. B. (1975). The social psychology of jury deliberations. In R. Simon (Ed.) The Jury System in America: A Critical Overview. Beverly Hills, CA: Sage.

Koehler, J. J. (2001). When are people persuaded by DNA match statistics? Law and Human Behavior, 25, 493-513. doi:10.1023/A:1012892815916

Kovera, M. B., Gresham, A. W., Borgida, E., Gray, E., \& Regan, P. C. (1997). Does expert psychological testimony inform of influence juror decision making? A social cognitive analysis. Journal of Applied Psychology, 82, 178-191. doi:10.1037/00219010.82 .1 .178

Lieberman, J. D., Carrell, C. A., Miethe, T. D., \& Krauss, D. A. (2008). Gold versus platinum: Do jurors recognize the superiority and limitations of DNA evidence compared to other types of forensic evidence? Psychology, Public Policy, and Law, 14, 27-62. doi:10.1037/1076-8971.14.1.27

Lilienfeld, S. O., \& Widows, M. (2005). Professional manual for the psychopathic personality inventory-revised (PPI-R). Lutz, FL: Psychological Assessment Resources.

MacCoun, R. J., \& Kerr, N. L. (1988). Asymmetric influence in mock jury deliberation: Jurors' bias for leniency. Journal of Personality and Social Psychology, 54, 21-33. doi:10.1037/0022-3514.54.1.21 
Madrigal, A. (2009, November 9). Courtroom first: Brain scan used in murder sentencing. Wired Science. Retrieved from http://www.wired.com

Maryland v. Rose, Unpublished decision (MD Cir. 2007).

McAllister, H. A., \& Bregman, N. J. (1986). Juror underutilization of eyewitness nonidentifications: Theoretical and practical implications. Journal of Applied Psychology, 71, 168-170. doi:10.1037/0021-9010.71.1.168

McCabe, D. P., \& Castel, A. D. (2008). Seeing is believing: The effect of brain images on judgments of scientific reasoning. Cognition, 107, 343-352. doi:10.1016/j.cognition.2007.07.017

McCabe, D. P., Castel, A. D., \& Rhodes, M. G. (2011). The influence of fMRI lie detection evidence on juror decision-making. Behavioral Sciences and the Law, 29, 566-577. doi:10.1002/bsl.993

Mobbs, D., Lau, H. C., Jones, O. D., \& Frith, C. D. (2007). Law, responsibility, and the brain. PLoS Biology, 5, 693-700. doi:10.1371/journal.pbio.0050103

Myers, B., \& Arbuthnot, J. (1997). Polygraph testimony and juror judgments: A comparison of the guilty knowledge test and the control question test. Journal of Applied Social Psychology, 27, 1421-1437. doi:10.1111/j.1559-1816.1997.tb01606.x

Myers, B., Latter, R., \& Abdollahi-Arena, M. K. (2006). The court of public opinion: Lay perceptions of polygraph testing. Law and Human Behavior, 30, 509-523. doi:10.1007/s10979-006-9041-0

Myers, B., Rosol, A., \& Boelter, E. (2003). Polygraph evidence and juror judgments: The effects of corroborating evidence. Journal of Applied Social Psychology, 33, 948-962. doi:10.1111/j.1559-1816.2003.tb01933.x 
National Research Council of the USA. (1992). DNA technology in forensic science. Washington, DC: National Academy Press.

People v. Wesley, 553 N.Y.S. 2d 643 (New York Sup. Ct. 1988).

Qian, X., \& Wei, L. (2012). The VDS based compressed sensing for abdomen MRI. ACMA, 1, 12-16. Retrieved from http://worldsciencepublisher.org Raine, A. (2008). From genes to brain to antisocial behavior. Current Directions in Psychological Science, 17, 323-328. doi:10.1111/j.1467-8721.2008.00599.x

Rigoni, D., Pellegrini, S., Mariotti, V., Cozza, A., Mechelli, A. Ferrara, S. D.,...Sartori, G. (2010). How neuroscience and behavioral genetics improve psychiatric assessment: Report on a violent murder case. Frontiers in Behavioral Neuroscience, 4, 1-10. doi:10.3389/fnbeh.2010.00160

Roper v. Simmons, 543 U.S. 551 (2005).

Rosen, J. (2007, March 11). The brain on the stand. The New York Times. Retrieved from http://www.nytimes.com

Saenz, A. (2009, December 2). fMRI used as evidence in sentencing for murderer. Singularity Hub. Retrieved from http://www.singularityhub.com

Studebaker, C., Robbennolt, J., Penrod, S., Pathak-Sharma, M. Groscup, J., \& Devenport, J. (2002). Studying pretrial publicity effects: New methods for improving ecological validity and testing external validity. Law and Human Behavior, 26, 19-41. doi:10.1023/A:1013877108082

United States v. Alexander, 526 F. 2d 161, 168 (8th Cir. 1975).

United States v. Plaza, Acosta, \& Rodriguez, 188 F. Supp. 2d 549 (E.D. Pennsylvania 2002). United States v. Scheffer, 523 U.S. 303 (1998). 
Vidmar, N., \& Hans, V. P. (2007). Death is different: Juries and capital punishment. American Juries: The Verdict (pp. 241-265). Amherst, NY: Prometheus Books.

Weisberg, D. S., Keil, F. C., Goodstein, J., Rawson, E., \& Gray, J. R. (2009). The seductive allure of neuroscience explanations. Journal of Cognitive Neuroscience, 20, 470-477. doi:10.1162/jocn.2008.20040

Williams, A., Cheyne, A., \& MacDonald, S. (2001). The public's knowledge of psychiatrists: Questionnaire survey. The Psychiatrist, 25, 429-432. doi:10.1192/pb.25.11.429 
Table 1

Proportion of guilty verdicts by evidence condition.

\begin{tabular}{lc}
\hline Evidence & \\
Condition & Guilt \\
\hline MRI + Images & .42 \\
MRI & .57 \\
Control & .44 \\
\multicolumn{2}{c}{ Overall } \\
\hline
\end{tabular}


Table 2

Mean ratings of guilt and confidence by condition.

\begin{tabular}{lcc}
\hline \multicolumn{1}{c}{ Evidence } & Guilt & Confidence \\
\cline { 2 - 3 } Condition & $M(S D)$ & $M(S D)$ \\
\hline MRI + Images & $3.86(0.93)$ & $4.22(1.12)$ \\
MRI & $4.12(0.88)$ & $4.03(0.99)$ \\
Control & $4.36(1.07)$ & $4.31(1.01)$ \\
\multicolumn{1}{c}{ Overall } & $4.11(0.98)$ & $4.18(1.04)$
\end{tabular}

Note. Mean ratings of guilt and confidence range from not at all (1) to very (6). Appendix D contains question 2 (likelihood of guilt) and question 3 (confidence in verdict). 
Table 3

Correct responses to the "general facts of the case" questions of the manipulation check.

Percent

Question

Total N Correct

What was the alleged murder weapon?

$109 \quad 99.1$

Which witness did not testify?

$109 \quad 99.1$

When asked why there was no blood...?

$109 \quad 99.1$

What is the name of the defendant?

$109 \quad 96.3$

Note. Questions are located in Appendix E. 
Table 4

Correct responses to the "MRI" questions of the manipulation check.

Percent

Question

Total N Correct

Givens had all of the following except...?

$73 \quad 57.5$

MRI can conclusively demonstrate what?

$\begin{array}{ll}73 & 39.7\end{array}$

The results of the MRI demonstrated what?

$73 \quad 89.0$

Note. Questions are located in Appendix E. 
Appendix A

\section{Juror Decision Making Study}

Please complete the following questions to provide the researchers with basic demographic information. Circle the correct response or fill in the blank with the appropriate information.

Sex: $\quad$ Male $\quad$ Female

Age:

Year in school: $\quad$ Freshman

Sophomore

Junior

Senior

Are you a U.S. citizen?

Yes

No

Have you ever served as a juror?

Yes

No 
Appendix B

\section{New York v. Givens}

1. What follows is a summary of the criminal trial proceedings in the case of New York v. Givens. The defendant, Brad Givens, was charged with two counts of murder.

2. In his opening statement, the prosecutor claimed the evidence will show that Brad Givens strangled his wife to death and stabbed a neighbor, Scott Maddox. Givens denies involvement in the murders, but the evidence will prove that he had the motive, means, and opportunity. Givens went crazy when his wife, Marylou, asked for a separation, leaving him to rent an apartment. Obsessed and suspicious that she was having an affair, he hired a private investigator to follow her and was frustrated when nothing turned up. Givens was in a "fragile" and "explosive" emotional state.

3. Continuing his opening statement, the prosecutor outlined his theory of the case. On the night of the murder, Givens came home and found Scott Maddox, a neighbor, in the kitchen with Marylou. He flew into a fit of rage and stabbed Maddox repeatedly in the chest. Marylou may have tried to stop the attack, but Givens strangled her. He then fled, disposed of his knife and eventually called the police. Realizing that he was seen running from the house, and that his fingerprints were all over the place, Givens came up with a story - that Maddox and his wife were already dead when he arrived.

4. The defense attorney opened by claiming that all the evidence is purely circumstantial. After all, Givens never confessed, no murder weapon was found, and nobody saw what happened. The defense attorney argued that the State's assessment of Givens' explosive emotional state was exaggerated. Givens admitted he was jealous, but the evidence will show that he was in control of his emotions that night and was trying to rebuild his life.

5. Continuing his opening statement, the defense explained that Givens went home that night to get some personal belongings. When he arrived, he found the victims dead. He checked them and then tried to revive his wife. In shock, Givens ran out of the house. After a few minutes, he managed to compose himself. He called the police and waited for them to arrive. A man is not guilty of murder simply because he was jealous. Once all the facts are in, it will be clear that the prosecution has failed to prove its case.

6. The first witness for the prosecution was David Prescott, the private investigator Givens had hired. Prescott said that Givens thought his wife was having an affair, but that he found no proof of it. Givens had paid him $\$ 3,000$ and seemed frustrated by the result. He pulled Prescott off the case four days before the murder "even though I'm sure she's screwing around". The defense lawyer objected to this last remark because it was hearsay. However, the judge overruled the objection. 
7. On cross examination, Prescott said he was surprised he wasn't let go sooner than he was. He described Givens as a cool-headed guy who still loved his wife. The prosecuting attorney objected to this characterization as just an opinion. The judge sustained the objection, so Prescott restated his testimony: "Givens acted like he loved his wife".

8. The next witness was Ed Johnson, one of two police officers to meet Givens at the house. Johnson met Givens outside at 8:40 pm and then went in to inspect the bloody crime scene. Johnson described how he found the bodies, fully clothed, and on the floor of the kitchen. He immediately secured the area while a forensic examiner took photographs. There was no evidence of a forced entry and there was nothing missing from the house. Johnson arrested Givens, read him his rights, and took him in for questioning.

9. On cross-examination, Johnson said that no weapon was ever recovered and described the defendant as deeply upset over his wife's death. When asked why Givens was charged without any hard evidence, Johnson said that his story just didn't make sense, even before they knew of his marital problems.

10. The next witness, Dr. Ronald Tinsworth, a psychiatrist, presented the results of a personality evaluation and scans from Givens' brain using magnetic resonance imaging (MRI). According to the results of his personality evaluation, Tinsworth claims that Givens has an unusually high tendency to act impulsively without thinking and to take risks and seek thrills. The results of the MRI demonstrate reduced gray matter density in the left middle and superior frontal gyrus of Givens' brain. Similar reductions in gray matter are shown in individuals with impulsive tendencies and poor inhibitory control.

11. On cross-examination, Dr. Tinsworth stated that MRI is a useful medical and diagnostic tool, but that reduced gray matter are not conclusive of impulsive tendencies and poor inhibitory control specific to the results of personality evaluations. Furthermore, some scientists have argued that structural differences in the brain do not always suggest personality disorder.

12. The State's next witness was Dr. Neil Gravane, coroner in the case. Gravane testified that Maddox died of a 2-inch laceration of the chest, probably caused by a hunting knife with a curved edge. Based on the height and angle of the wounds, Dr. Gravane concluded that the killer used his right hand and stood about 6-feet tall, like the defendant. Marylou Givens died of a shortage of oxygen and had a deep bruise on her throat, indicating she was strangled.

13. On cross-examination, Gravane conceded that the murder weapon was a common type of knife and is readily available. The State objected that a medical doctor is not qualified to speculate on matters of availability. The judge overruled the objection. On further crossexamination, Gravane admitted that his estimate of the killer's height was just that, an estimate, not a fact. 
14. The final witness for the prosecution was Jeffrey Ostrander. Ostrander testified that he was sitting in his car waiting for his girlfriend the night of the murder. Suddenly, he saw someone run out the front door of the Givens house with something in his hand, and drive off.

15. On cross-examination, Ostrander said it was dark and that he wasn't sure what the man he saw was holding in his hand. On further questioning, he said he could not tell whether the man he saw was the defendant. He also conceded that he had no idea of what actually happened inside the house or why the man he saw came running out.

16. The first witness for the defense was Joe Davis, a friend of Brad Givens. According to Davis, he and Givens had drinks at a local bar the night of the murders and Givens admitted that he had overreacted to his wife's request for a separation. Davis said that on that night Givens was calm and "in control of his emotions". The two men had "only a couple of beers" and then parted because Givens wanted to return home to get some stuff from his desk.

17. On cross-examination, Davis admitted that Givens had in the past expressed "frustration" about his wife. He also admitted that he and Givens had hunted together and that Givens owned at least one hunting knife. That night, he said that he and Givens left the bar at 7:30 $\mathrm{pm}$ and that the drive home took fifteen minutes. Davis was asked if he was such a good friend to Givens that he might lie for him. The defense attorney objected to this question as argumentative. The judge sustained the objection and instructed the jury to disregard it.

18. Next the defense called Givens. Givens conceded that he hired an investigator, but then he called it off. He said that on the night of the murder, he had a couple of beers with Davis, went home to get some stuff, and saw his wife and Maddox dead in the kitchen. He said he touched Maddox to see if he was alive and then tried to revive his wife. Describing himself as "in shock", Givens left the house and eventually called the police. He denied having anything to do with the murders.

19. On cross-examination, Givens was asked where he went in the time before he called the police. He said he just drove around for awhile. He was scared and didn't know what to do. Eventually he went to his apartment, about a mile from the house, and called the police.

When asked why there was no blood on his hands if he had touched Maddox, Givens said he had no idea. After intense probing, he said "I don't remember. Maybe I washed it off".

20. The prosecutor began his closing argument by reminding the jury that two innocent people were senselessly murdered, leaving behind four grieving parents, seven brothers and sisters, and other loved ones. "For these living victims, whose lives will never be the same, ladies and gentleman, justice will not be served until the man responsible for these brutal deaths is punished". 
21. Summarizing the evidence, the prosecuting attorney noted that Givens was consumed by such intense jealousy that he paid $\$ 3,000$ to a private investigator. He fit the physical profile of the killer and had a key to the house, which is why there was no sign of a forced entry. He also left fingerprints all over the place, especially in the kitchen and on his wife, despite the fact that he had moved out weeks earlier. The weapon was never found, but Givens did own hunting knives and had ample time to dispose of the weapon. He also had no alibi; not a single person saw him in the half hour it took him to call the police. In light of all the evidence, the defendant should be found guilty of two counts of first-degree murder.

22. The defense lawyer began the closing argument by acknowledging that Brad Givens is an emotional man. Emotion made him rush to his wife when he found her dead, and then it made him flee the scene in shock. But we also heard from Givens' friend that he was in control of his emotions that night and had come to accept the fact that he and his wife were separated.

23. Givens' actions after the crime were not those of a guilty man. He called the police, waited for them to arrive, and then cooperated. He was noticeably saddened by the death of his wife. So just what is the case against Givens? There was no confession, no weapon, and no eyewitness, only weak circumstantial evidence. "You can't convict a man of murder because he is 6-feet tall, owns hunting knives, and is upset over being separated from his wife". The defense attorney concluded by arguing that the State failed to prove its case beyond a reasonable doubt and that Givens should be found not guilty.

24. The judge told jurors that all the relevant and material facts were in and that their duty was to deliberate until they reached a unanimous verdict. In determining the defendant's guilt or innocence, he said, one may consider his action before, during, and after the crime was committed. The judge reminded the jury that the defendant is presumed innocent and that the State has the burden to prove guilt beyond a reasonable doubt. 
Appendix C
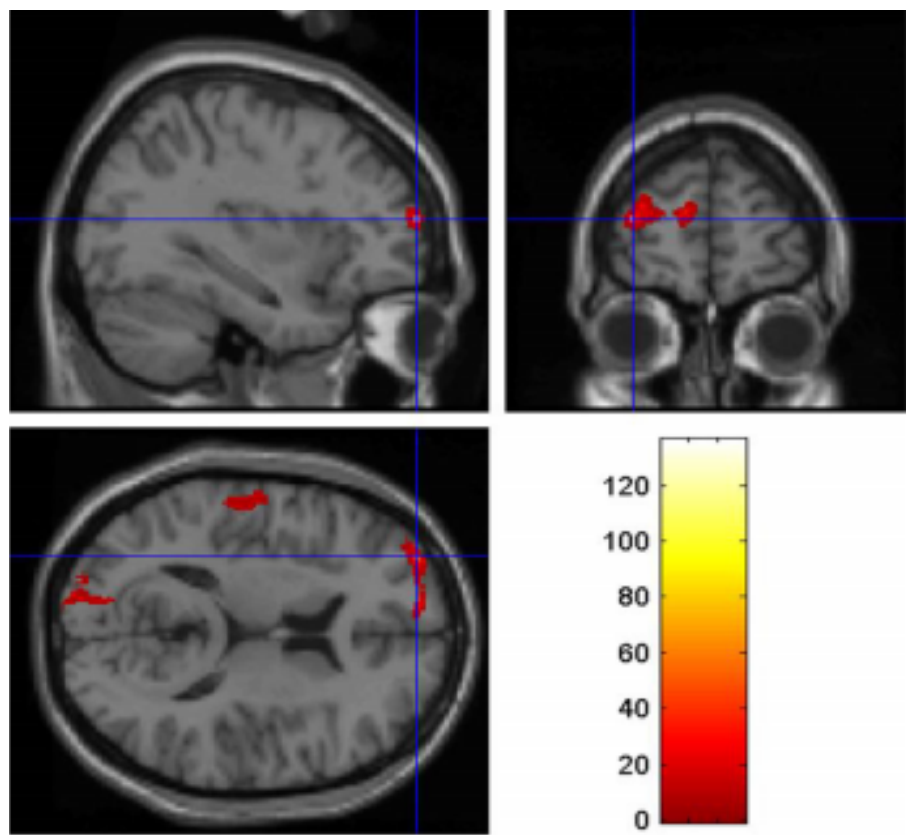

Figure 1 | Region of the left middle frontal gyrus showing reduced gray matter density in Givens' brain relative to healthy control participants.
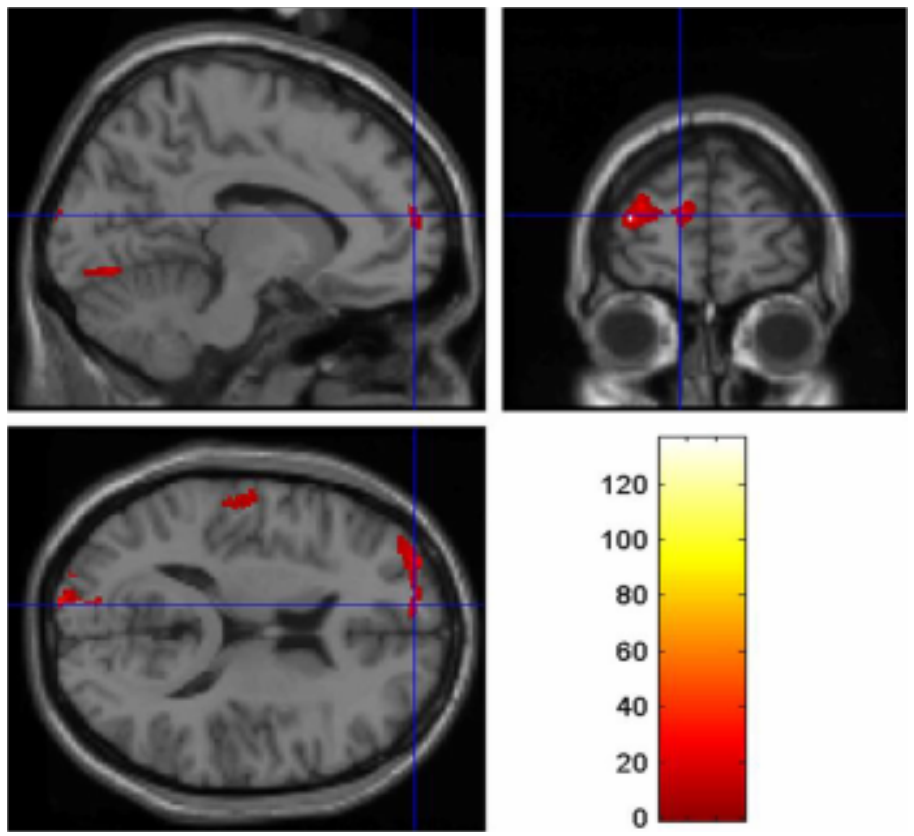

Figure 2 | Region of the left superior frontal gyrus showing reduced gray matter density in Givens' brain relative to healthy control participants. 
Appendix D

For the following questions please circle the appropriate answer. One question requires you to fill in the blank.

1. If you were a juror for this trial, would you find the defendant guilty or not guilty?

Not guilty

2. How likely is it that the defendant is guilty?

\section{Guilty}

Very likely

$\begin{array}{llllll}1 & 2 & 3 & 4 & 5 & 6\end{array}$

3. How confident are you in your decision?

Not at all confident

1
2

3

4

Very confident

$5 \quad 6$

4. Which piece of evidence was most influential in your verdict? Please indicate the number from the trial summary (the paragraphs in the summary are numbered for your reference).

Indicate the number here:

5. How influential to your decision was this piece of evidence on your final verdict?

Not at all influential

1

3

4

6

6. Overall, how influential was the evidence presented by the prosecution?

Very weak

1

3

4

5

Very strong

7. Overall, how influential was the evidence presented by the defense?

Very weak

1

3

4

5

Very strong 
8. How influential to your decision was the testimony of David Prescott, the private investigator, regarding Givens' alleged jealous behavior?

Not at all influential

1
2

3
Very influential

$5 \quad 6$

9. Based on your opinion, how accurate was David Prescott's testimony?

Not at all accurate

1

3

4

5

Very accurate

10. How influential to your decision was the testimony of Ed Johnson, the police officer, regarding the scene of the crime?

\section{Not at all influential}

1

2

3

4

Very influential

11. Based on your opinion, how accurate was Ed Johnson's testimony?

Not at all accurate

1

3

4

Very accurate

12. [If participants received MRI evidence] How influential to your decision was the testimony of Dr. Ronald Tinsworth, the MRI expert, regarding Givens' mental state?

Not at all influential

1
2

3

4

Very influential

13. [If participants received MRI evidence] Based on your opinion, how accurate was Dr. Ronald Tinsworth's testimony?

Not at all accurate

1
2
3
Very accurate

4

5 
14. [If participants received MRI evidence] Based on your opinion, how accurate was the MRI evidence with regard to the defendant's mental state?

Not at all accurate

1

2

3

4

6

15. How influential to your decision was the testimony of Dr. Neil Gravane, the coroner, regarding the hunting knife wound?

Not at all influential

1
2

3

4

ery influential

16. Based on your opinion, how accurate was Dr. Neil Gravane's testimony?

Not at all accurate

1

2

3

4

Very accurate

17. How influential to your decision was the testimony of Jeffrey Ostrander, the eyewitness who saw someone leaving Givens' house?

Not at all influential

1

2

3

4

18. Based on your opinion, how accurate was Jeffrey Ostrander's testimony?

Not at all accurate

Very accurate

1

2

3

4

5

6

19. How influential to your decision was the testimony of Joe Davis, the friend of Givens, regarding Givens' emotional control at the bar?

Not at all influential

1
2
3
Very influential

4

5

6 
20. Based on your opinion, how accurate was Joe Davis' testimony?

Not at all accurate

1 2

3

4

5

Very accurate

5

6

21. How influential to your decision was the testimony from Brad Givens himself?

Not at all influential

1

3

4

Very influential

22. Based on your opinion, how accurate was Brad Given's testimony?

Not at all accurate

1

2

3

4

5

6 
Appendix E

1. What was the alleged murder weapon?
a. Gun
b. Rope
c. Poison
d. None of the above

2. [If participants received MRI evidence] Dr. Ronald Tinsworth concluded that Givens had all of the following behavioral tendencies except?
a. Increased risk seeking behavior
b. Tendency to act impulsively
c. Increased tendency to seek thrills
d. Tendency to anger easily

3. Which witness did not testify?
a. Jake Acton, bartender
b. Brad Givens, defendant
c. David Prescott, private investigator
d. Dr. Neil Gravane, coroner

4. When asked why there was no blood on his hands, what did Givens reply?
a. "I didn't touch the blood."
b. "I don't want to answer."
c. "I don’t know. Maybe I washed it off."
d. None of the above 
5. [If participants received MRI evidence] MRI can conclusively demonstrate which of the following?
a. The defendant is psychopathic
b. Individuals with reduced gray matter are more impulsive
c. The defendant's actions were excusable because of the brain damage
d. None of the above

6. What is the name of the defendant in the trial?
a. Ed Johnson
b. Neil Gravane
c. Brad Givens
d. None of the above

7. [If participants received MRI evidence] The results of the MRI demonstrated which of the following?
a. Increased blood flow to the orbitofrontal cortex
b. Reduced gray matter density in left superior frontal gyrus
c. Slower brain processing speed than normal
d. None of the above 